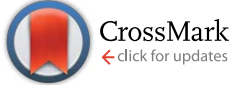

Cite this: RSC Adv., 2017, 7, 2971
Received 17th November 2016 Accepted 5th December 2016

DOI: $10.1039 / c 6 r a 26946 j$

www.rsc.org/advances

\section{Nitrile functionalized graphene oxide for highly selective sulfonated poly(arylene ether nitrile)- based proton-conducting membranes}

\begin{abstract}
Mengna Feng, Tao Cheng, Xu Huang, Yumin Huang* and Xiaobo Liu*
4-(3-Aminophenoxy)phthalonitrile grafted graphene oxide (APN-GO) was employed as the filler incorporated into a sulfonated poly(arylene ether nitrile) (SPEN) matrix. The resulting composite membranes show good dispersion and compatibility, which is confirmed through scanning electron microscope. In this process, the existence of hydrogen bonds between amide and sulfonic acid groups can improve the interfacial adhesion and compatibility between the filler and the matrix. Besides, the newly introduced polar nitrile of APN-GO also can increase the intermolecular interaction and make the membranes more compact, which is favorable for the reduction of methanol permeability. Moreover, the composite membranes exhibit improved dimensional stability, proton conductivity and methanol permeability compared to that of a pure SPEN membrane. Furthermore, the composite membrane with $2 \mathrm{wt} \%$ filler achieves a high proton conductivity $\left(0.124 \mathrm{~S} \mathrm{~cm}^{-1}\right.$ at $20{ }^{\circ} \mathrm{C}$ and $0.240 \mathrm{~S} \mathrm{~cm}^{-1}$ at $80{ }^{\circ} \mathrm{C}$ ) and low methanol permeability $\left(0.117 \times 10^{-6} \mathrm{~cm}^{2} \mathrm{~s}^{-1}\right.$ at $\left.20^{\circ} \mathrm{C}\right)$ simultaneously, and exhibits a much higher selectivity $\left(10.598 \times 10^{5} \mathrm{~S} \mathrm{~s} \mathrm{~cm}^{-3}\right)$ than that of Nafion $117\left(0.45 \times 10^{5} \mathrm{~S} \mathrm{~s} \mathrm{~cm}^{-3}\right)$. All results indicate the potential of the as-prepared composite membranes for direct methanol fuel cell applications.
\end{abstract}

\section{Introduction}

Direct methanol fuel cells (DMFCs), which can convert chemical energy into electrical energy at a high efficiency without any pollutant emission, have been developed as an environmental friendly power source for portable applications. ${ }^{1-3}$ A proton exchange membrane (PEM) as a core constituent of the DMFCs is the key factor in transporting proton systems, providing protons and preventing the mixing of fuel gas and oxidants. ${ }^{\mathbf{4}, 5}$ Furthermore, the desired PEMs are considered to possess high proton conductivity, excellent mechanical properties, outstanding thermal stability, low methanol permeability and low cost. Currently, the state-of-the-art PEM is DuPont's Nafion membranes due to the high inherent conductivity. However, the Nafion membranes suffer from high cost, difficult synthetic procedures and high methanol permeability, restricting the applications in fuel cells. ${ }^{6-9}$

As effective alternatives, sulfonated poly(arylene ether nitrile) (SPEN) has been broadly investigated owing to their excellent thermal properties and oxidation resistance. ${ }^{\mathbf{1 0 - 1 4}}$ Moreover, polar nitrile groups in sulfonated aromatic polymers could decrease the swelling of the membranes and promote the adhesion property between the membrane and catalyst

High Temperature Resistant Polymer and Functional Composites Key Laboratory of Sichuan Province, School of Microelectronics and Solid-States Electronics, University of Electronic Science and Technology of China, Chengdu 610054, China. E-mail: hym@uestc.edu.cn; liuxb@uestc.edu.cn; Tel: +86-28-83207326 layer. ${ }^{\mathbf{1 5 , 1 6}}$ Like other aromatic polymers, SPENs with high degree of sulfonation are required for the ideal PEMs. However, high sulfonation levels may lead to swelling or dissolution while the fuel cell systems are working. Organic-inorganic hybridization is an effective method for solving this problem. Studies have shown that the introduction of inorganic fillers can greatly improve the comprehensive performance of SPENs. ${ }^{17-19}$

As is known, graphene oxide (GO) possesses a typical pseudo-2D structure containing various oxygen functional groups, such as epoxide, hydroxyl, and carbonyl groups, and has received wide attention due to its excellent properties. ${ }^{20,21}$ Recently, a variety of modified GO structures have been incorporated into the polymer matrix to obtain organic-inorganic composite membranes as PEMs. ${ }^{22-27}$ Although some significant progress has been made, the development of new composite membranes, which meet the ideal PEM, is still in high demand. One challenge that still needs to be faced is the improvement of the interfacial compatibility between the modified GO and the polymer matrix. In addition, selectivity, namely, the ratio of proton conductivity to methanol permeability, also needs to be improved.

The dispersion of GO in the polymer matrix is the most important factor to improve interfacial interactions and obtain polymer composites with excellent properties, which are determined by the introduction of functional groups into GO. As is known, the cyano group that is "strongly polar" can increase the intermolecular interaction between the polymer chains and make the membranes more compact, which is 
favorable for the reduction of methanol permeability without significantly decreasing the conductivity. ${ }^{28-30}$ Thus, the cyano group is introduced into GO, which is expected to improve the interfacial adhesion and compatibility of GO and SPEN, resulting in composite membranes with a good balance between methanol permeability and proton conductivity. Moreover, the amide bonds are designed as a bridging group between GO and the matrix, which not only can be easily constructed, but also form hydrogen bonds with sulfonic acid groups, providing more proton transport channel for the hopping of protons.

In this study, nitrile functionalized graphene oxide (APN-GO) was synthesized as a filler. The effect of the APN-GO content on the structure and properties of SPEN membranes was extensively investigated. This study also provided a simple and new route for obtaining highly selective proton-conducting membranes. In addition, detailed descriptions of the composite membrane properties, such as thermal and mechanical properties, proton conductivity and methanol permeation, were studied.

\section{Experimental}

\subsection{Materials}

2,6-Difluorobenzonitrile (DFBN), potassium 2,5-dihydroxybenzenesulfonate (SHQ), and 4,4'-biphenol (BP) were supplied by Sigma Aldrich. Phosphoric acid $\left(\mathrm{H}_{3} \mathrm{PO}_{4}\right)$ and hydrochloric acid ( $\mathrm{HCl})$ were purchased from Chengdu Haihong Chemical Co. N-Methylpyrrolidone (NMP, AR), dimethyl acetamide (DMAc, AR), toluene (AR), $N, N$-dimethylformamide (DMF, AR) and potassium carbonate $\left(\mathrm{K}_{2} \mathrm{CO}_{3}, \mathrm{AR}\right)$ were supplied by Tianjin BODI chemicals. APN was synthetized in our laboratory according to a previous report. ${ }^{31}$ Isophorone diisocyanate (IPDI) and stannous octoate were purchased from Shanghai Hengyi Co. Ltd. (Shanghai, China). Graphene oxide was provided by XFNANO Materials Tech Co. Ltd. (Nanjing, China). All the materials were used without further purification.

\subsection{Synthesis of SPEN}

The SPEN was synthesized via nucleophilic aromatic substitution reaction with DFBN, BP and SHQ (the molar ratio was $1: 0.3: 0.7)$ in NMP with $\mathrm{K}_{2} \mathrm{CO}_{3}$ as the catalyst. The detailed synthesis process was referring to the previous literature. ${ }^{19}$

\subsection{Preparation of APN grafted graphene oxide (APN-GO)}

GO was obtained using the modified Hummers method from natural flake graphite. ${ }^{32}$ The preparation of APN-GO was conducted in two steps. Firstly, $0.1 \mathrm{~g}$ of GO was dispersed into 100 $\mathrm{mL}$ of anhydrous DMF $\left(1.0 \mathrm{mg} \mathrm{mL} \mathrm{m}^{-1}\right)$ and then treated with ultrasonic oscillation for $1 \mathrm{~h}$ to prepare the GO suspension. After that, the suspension was shifted to a round-bottom flask with magnetic stirring under a nitrogen atmosphere. Then, 10 $\mathrm{mL}$ of IPDI was added and the reaction was refluxed for $7 \mathrm{~h}$ at $50{ }^{\circ} \mathrm{C}$. The mixture was washed with DMF solvent, sonicated for 10-20 min and then filtered to remove the unreacted IPDI. Secondly, $10 \mathrm{~g}$ APN, $100 \mathrm{~mL}$ DMF and two drops of stannous octoate were mixed together and refluxed for $5 \mathrm{~h}$ at $85^{\circ} \mathrm{C}$. After being washed and filtered with DMF several times to remove the unreacted monomer, the targeted APN-GO was obtained. The detailed synthesis process is shown in Scheme 1.

\subsection{Synthesis of APN-GO/SPEN membranes}

The APN-GO/SPEN composite membranes were fabricated by the facile solution-casting method. The different content of APN-GO powder ( $0 \mathrm{wt} \%, 0.5 \mathrm{wt} \%, 1 \mathrm{wt} \%, 2 \mathrm{wt} \%$ and $3 \mathrm{wt} \%$ in the total mass of $2 \mathrm{~g}$ ) were dispersed into $10 \mathrm{~mL}$ DMAc for $1 \mathrm{~h}$ by the ultrasonic dispersion technique. Simultaneously, the residual mass of SPEN was dissolved in $20 \mathrm{~mL}$ DMAc/deionized water $(5: 1, \mathrm{v} / \mathrm{v})$ mixed solvent. Then, the APN-GO solution was added into the abovementioned SPEN solution and kept ultrasounding for $2 \mathrm{~h}$ under continuous stirring to ensure uniform mixing of APN-GO in the SPEN matrix. Finally, the mixture suspension was cast onto a glass plate, dried at $80{ }^{\circ} \mathrm{C}$ for $2 \mathrm{~h}$, and then subsequently heated gradually at $100{ }^{\circ} \mathrm{C}, 120{ }^{\circ} \mathrm{C}$, $140{ }^{\circ} \mathrm{C}$, and $160{ }^{\circ} \mathrm{C}$ each for $2 \mathrm{~h}$ in a vacuum oven to obtain the composite membranes with different APN-GO contents ( $0 \mathrm{wt} \%$, $0.5 \mathrm{wt} \%, 1 \mathrm{wt} \%, 2 \mathrm{wt} \%$ and $3 \mathrm{wt} \%$ ). The GO/SPEN membranes were also prepared using a similar procedure. The corresponding acid form composite membranes were obtained by immersing the potassium form into $1 \mathrm{M} \mathrm{H}_{2} \mathrm{SO}_{4}$ for $24 \mathrm{~h}$ at room temperature.

\subsection{Characterization of polymers and membranes}

Fourier transform infrared (FTIR) spectra of GO and APN-GO were recorded on a Shimadzu FTIR8400S FTIR spectrometer in $\mathrm{KBr}$ pellets. The morphologies of the cross-sectional samples, obtained by brittle fracture in liquid nitrogen and decoration with gold layer, were observed using a scanning electron microscope (SEM, JEOL JSM-5900 LV). The XPS spectrum was recorded on an ESCA 2000 (VG Microtech, UK) using a monochromic Al Ka source. TGA (thermogravimetric analysis) was conducted on a TA Instruments Q50 series analyzer system under nitrogen atmosphere at a heating rate of $20{ }^{\circ} \mathrm{C} \mathrm{min}^{-1}$. The mechanical properties of the membranes were investigated using a SANS CMT6104 series desktop electromechanical universal testing machine, and the membranes were measured at $100 \% \mathrm{RH}$ and room temperature at a constant operating rate of $5 \mathrm{~mm} \mathrm{~min}^{-1}$.

To measure the water uptake and swelling ratio, all the membranes were dried at $80{ }^{\circ} \mathrm{C}$ for $24 \mathrm{~h}$, and the weights and lengths were marked as $W_{\text {dry }}$. After that, all the membranes were

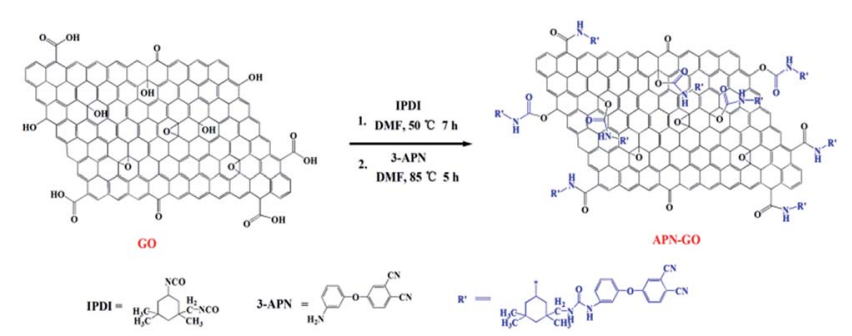

Scheme 1 The detail synthesis process of APN-GO. 
soaked in deionized water for $24 \mathrm{~h}$ at the appointed temperatures and then taken out and wiped with tissue paper quickly for weight measurement. The water uptake and swelling ratio of the membrane were calculated using the following formula:

$$
\begin{aligned}
& \text { Water uptake }(\%)=\frac{W_{\text {wet }}-W_{\text {dry }}}{W_{\text {dry }}} \times 100 \% \\
& \text { Swelling ratio }(\%)=\frac{L_{\text {wet }}-L_{\text {dry }}}{L_{\text {dry }}} \times 100 \%
\end{aligned}
$$

The proton conductivity was implemented via AC impedance method between the frequencies of $0.1 \mathrm{~Hz}$ to $100 \mathrm{kHz}$ with $50 \mathrm{mV}$ using an electrochemical work station (Model 600E Series electrochemical analyzer). The value of the proton conductivity was obtained using the following equation:

$$
\sigma=\frac{L}{R A}
$$

where $\sigma, L, R$ and $A$ represent proton conductivity, thickness, measured resistance, and membranes area, respectively.

The methanol permeability was conducted on the diffusion cell divided into two compartments by the membranes: one was added into hyperpure water $(\mathrm{A}, 20 \mathrm{~mL})$ and the other was added into a $10 \mathrm{M}$ methanol solution (B, $20 \mathrm{~mL}$ ). The diffusion cells were continuously stirred in the experiment. The methanol concentration in cell A was examined using a SHIMADZU GC-8A chromatograph, and the methanol permeability was calculated using the following equation:

$$
C_{\mathrm{B}}(t)=\frac{A}{V_{\mathrm{B}}} \frac{D K}{L} C_{\mathrm{A}}\left(t-t_{0}\right)
$$

where $A$ is the effective area, $L$ is the thickness of the membrane, and $V_{\mathrm{B}}$ is the volume of receptor reservoir. $C_{\mathrm{A}}$ and $C_{\mathrm{B}}$ are the methanol concentration in the donor and receptor reservoirs, respectively.

\section{Results and discussion}

\subsection{The characterization of APN-GO}

Fig. 1(a) shows the FTIR spectra of GO and APN-GO. Four characteristic peaks at $3421,1720,1220$, and $1065 \mathrm{~cm}^{-1}$ are identified as the stretching vibrations of $\mathrm{O}-\mathrm{H}, \mathrm{C}=\mathrm{O}, \mathrm{C}-\mathrm{OH}$, and $\mathrm{C}-\mathrm{O}$, respectively. ${ }^{33}$ The absorptions at 1392 and $1623 \mathrm{~cm}^{-1}$ are assigned to $\mathrm{C}-\mathrm{O}$ deformation and $\mathrm{C}-\mathrm{O}-\mathrm{C}$ stretching vibrations,
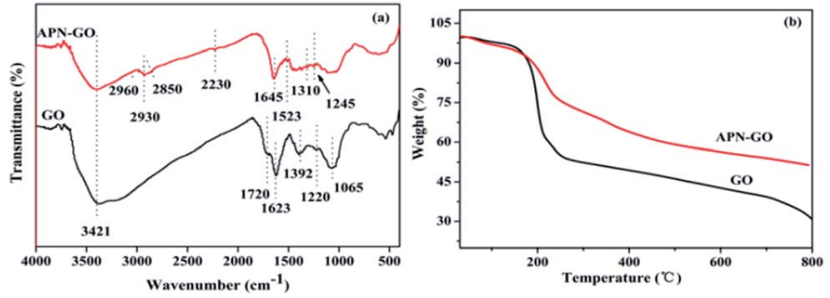

Fig. 1 (a) FTIR spectra and (b) TGA curves of GO and APN-GO. respectively. ${ }^{34}$ The appearance of these peaks demonstrates that graphite was successfully oxidized to graphene oxide. Compared with GO, the newly emerging characteristic peaks of APN-GO at 2960, 2930 and $2850 \mathrm{~cm}^{-1}$ are the antisymmetric stretching vibrations of methyl and methylene. The peaks at 2230 and $1245 \mathrm{~cm}^{-1}$ are the characteristic absorptions of $-\mathrm{CN}$ and the stretching vibration of the aromatic ether, respectively. In addition, the absorption peak of GO at $1720 \mathrm{~cm}^{-1}$ disappears, whereas the new bands of APN-GO at 1645, 1523, and $1310 \mathrm{~cm}^{-1}$ are observed, which are assigned to the carbonyl stretching vibration of carbamate esters and the characteristic absorption band of amide bonds. ${ }^{35}$

TGA was used to further confirm the formation of APN-GO, as shown in Fig. 1(b). GO contains various oxygen functional groups, such as carbonyl, epoxy, hydroxyl, and carboxylic acid groups which can be easily decomposed at $160-200{ }^{\circ} \mathrm{C}$. Compared with these two curves, the decomposition degree of GO and APN-GO is quite different, indicating that parts of the oxygen functional groups have been reacted as expected.

The XPS C1s deconvoluted spectra of GO, APN-GO, and N1s of APN-GO are shown in Fig. 2(a), (b) and (c) respectively. On
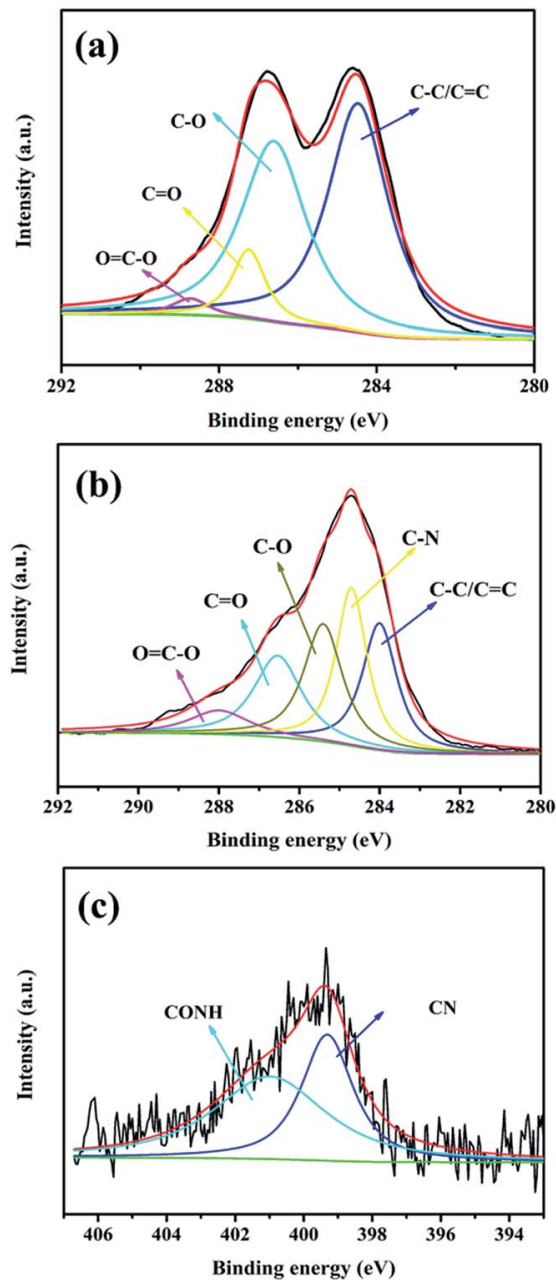

Fig. 2 C1s deconvoluted XPS spectrum of (a) GO and (b) APN-GO, and (c) N1s of APN-GO. 
comparison, with the addition of APN, in the APN-GO C1s spectrum, a new carbon species appears at $284.7 \mathrm{eV}$, corresponding to $-\mathrm{CN}$. In addition, the decreased intensity of $\mathrm{C}-\mathrm{O}$ peak indicates that the hydroxyl group of GO has been reacted with IPDI. Fig. 2(c) shows the N1s core-level spectrum, which consists of two components at 401.0 and $399.3 \mathrm{eV}$, assigned to the binding energies of the amide and nitrile of APN-GO. Therefore, the analysis of XPS, FTIR and TGA provides evidence that the APN-GO has been prepared successfully.

\subsection{SEM characterization}

The micromorphology and compatibility of SPEN and APN-GO were observed via SEM. The cross-sectional images of (a) pure SPEN, (b) $2 \mathrm{wt} \%$ APN-GO/SPEN at 8000 magnification time, (c and d) 3 wt\% APN-GO/SPEN and (e and f) 2 wt\% GO/SPEN membrane at 8000 and 12000 magnification times are shown in Fig. 3, respectively. From Fig. 3(b), it can be clearly seen that the interface of APN-GO and SPEN has no evident cracks or pinholes, presenting an excellent interfacial continuity and compatibility, which is better than that of GO and SPEN (Fig. 3(e) and (f)). This is attributed to the existence of hydrogen bonds and -CN, allowing the APN-GO to generate electrostatic interactions with the SPEN main chains, which can weaken the surface tension and control the elastic force of GO. ${ }^{25}$ This also proves that nitrile groups can better improve the interface compatibility of GO and SPEN, which is in agreement with
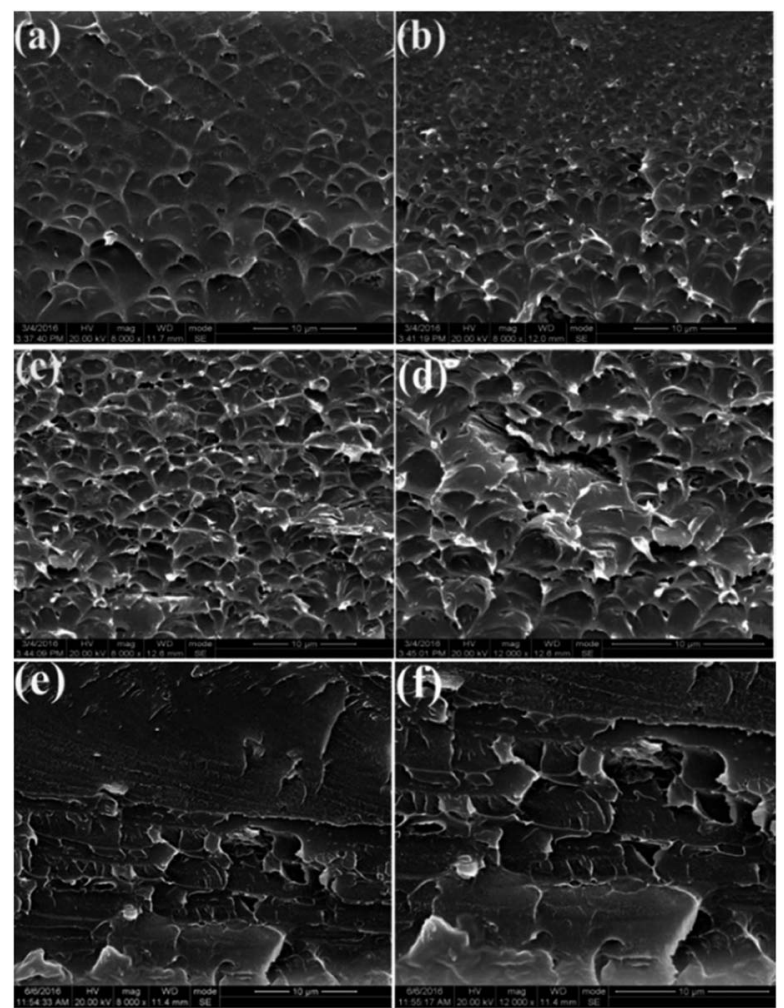

Fig. 3 The cross-sectional images of (a) pure SPEN, (b) 2 wt\% APNGO/SPEN at the 8000 magnification time, (c and d) 3 wt\% APN-GO/ SPEN and (e and f) 2 wt\% GO/SPEN membrane at 8000 and 12000 magnification times. previous study. ${ }^{36}$ Moreover, it can be observed that the $3 \mathrm{wt} \%$ APN-GO/SPEN membrane possesses a cruder interface and exhibits larger cracks and holes in Fig. 3(c) and (d). This is due to the appearance of phase separation between APN-GO and the SPEN matrix with the excess addition of fillers, which breaks the counterbalance of interface interactions between APN-GO and SPEN matrix. This phenomenon can be seen more clearly in Fig. 3(d).

\subsection{Thermal stability}

Fig. 4 shows the thermogravimetric analysis of pure SPEN and APN-GO/SPEN composite membranes. All the membranes exhibit two step degradation behaviors. The first stage of weight loss from $270{ }^{\circ} \mathrm{C}$ to $330{ }^{\circ} \mathrm{C}$ is due to the degradation of sulfonic acid groups, and the second stage around $400{ }^{\circ} \mathrm{C}$ is caused by decomposition of SPEN main chains. In addition, the 5\% weight loss temperatures of APN-GO/SPEN composite membranes are all above $350{ }^{\circ} \mathrm{C}$, indicating that these membranes possess excellent thermal stability. Compared with the pure SPEN, the composite membranes show a higher decomposition temperature, demonstrating that the thermal stability of SPEN is improved by the incorporation of APN-GO, which is caused by the fact that the grafted GO could capture the free radicals generated in the process of thermal decomposition. ${ }^{37}$

\subsection{Water uptake and swelling ratio}

The water uptake (WU) and swelling ratio (SR) of the pure SPEN, APN-GO/SPEN and GO/SPEN composite membranes at different temperatures are presented in Fig. 5 and 6, respectively. The pure SPEN membrane in an acid form swells excessively at a temperature of $80^{\circ} \mathrm{C}$ or higher, and therefore the WU and SR of the pure SPEN at $80{ }^{\circ} \mathrm{C}$ cannot be presented in Fig. 5. In general, the water molecules are very important in the proton conduction process for PEMs. From the figures, the WU and SR of both APN-GO/SPEN and GO/SPEN membranes are less than that of pure SPEN at relatively low temperatures, which is ascribed to the hydrogen bond interaction existing in both the composite membranes (sulfonic acid groups and amide of APNGO/SPEN or hydroxyl of GO/SPEN membranes). According to

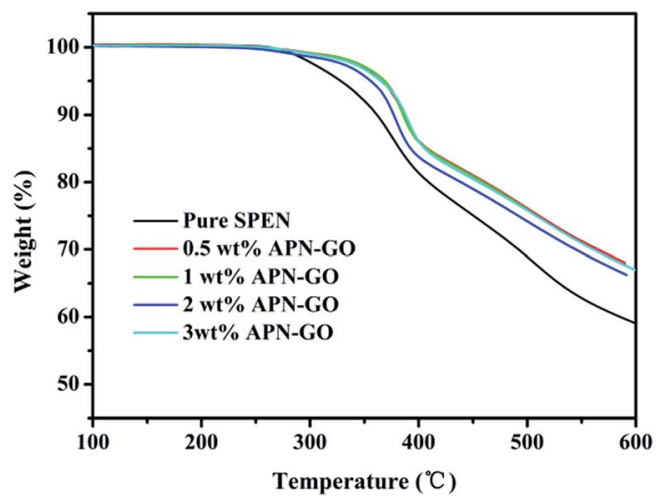

Fig. 4 TGA curves of pure SEPN and APN-GO composite membranes under an $\mathrm{N}_{2}$ atmosphere. 

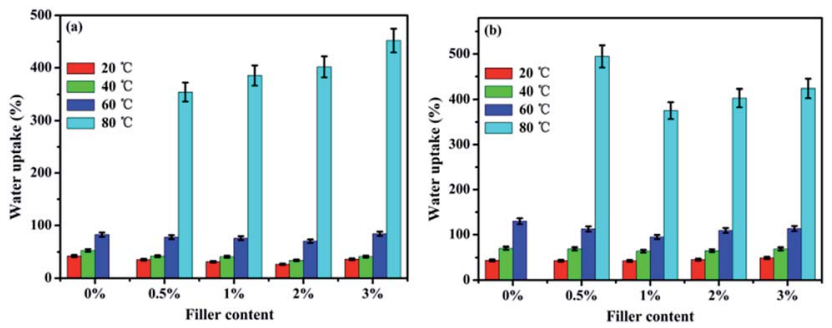

Fig. 5 The water uptake of (a) APN-GO/SPEN and (b) GO/SPEN composite membranes with different filler contents.

previous reports, the existence of a hydrogen bond interaction leads to a more compact membrane, reducing the WU and SR to some extent. ${ }^{38}$ In addition, the WU and SR of the APN-GO/SPEN membranes are slightly lower than that of the GO/SPEN composite membranes, indicating that the strong electron withdrawing cyano group in APN-GO can dramatically improve the interfacial adhesion and compatibility with the polymer matrix, which can also be confirmed by the SEM images. The results suggest that the GO and grafted GO have a positive effect on the reduction of water uptake and swelling.

\subsection{Mechanical properties}

Table 1 exhibits the tensile strength, tensile modulus, and elongation at break of the pure SPEN, GO/SPEN and APN-GO/ SPEN composite membranes measured in the full wet state. Both the tensile strength and modulus decrease with the addition of APN-GO and GO in the $100 \%$ wet state. After fully absorbing water, the plasticization effect of water could weaken the hydrogen bond interactions and reduce intermolecular forces, causing a decrease in the tensile strength and modulus. The $3 \mathrm{wt} \%$ APN-GO/SPEN composite membrane possesses the lowest tensile strength and modulus, which is mainly attributed to the bad interfacial adhesion caused by the phase separation between the filler and polymer matrix, resulting in the large interfacial permeation. Moreover, the plasticization effect of water also can increase the toughness of the membranes, which is identical with the results of elongation at break of the APNGO/SPEN composite membranes in the full wet state. In addition, the elongations at break values of APN-GO/SPEN membranes are superior to pure SPEN, indicating that the SPEN membrane is toughened by APN-GO in the wet state. The strength and toughness results are caused by the common
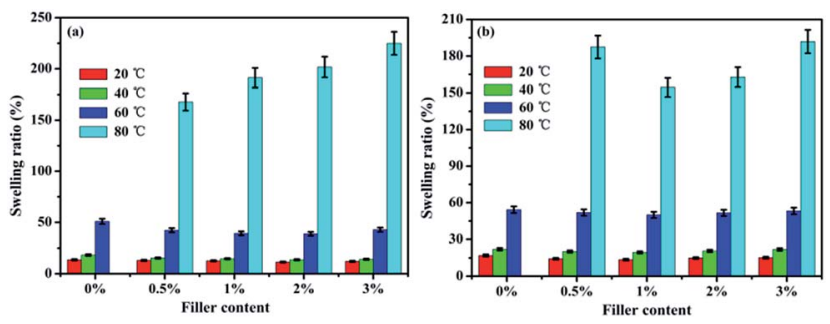

Fig. 6 The swelling ratio of (a) APN-GO/SPEN and (b) GO/SPEN composite membranes with different filler contents.
Table 1 The tensile strength, tensile modulus, and elongation at break of pure SPEN, GO/SPEN and APN-GO/SPEN composite membranes measured in the full wet state at room temperature

\begin{tabular}{llll}
\hline Filler content & $\begin{array}{l}\text { Tensile strength } \\
(\mathrm{MPa})\end{array}$ & $\begin{array}{l}\text { Tensile modulus } \\
(\mathrm{MPa})\end{array}$ & $\begin{array}{l}\text { Elongation at } \\
\text { break (\%) }\end{array}$ \\
\hline SPEN & 36 & 730 & 29 \\
$0.5 \mathrm{wt} \%$ APN-GO & 33 & 546 & 51 \\
1 wt\% APN-GO & 28 & 526 & 54 \\
$2 \mathrm{wt} \%$ APN-GO & 26 & 490 & 59 \\
3 wt\% APN-GO & 23 & 445 & 36 \\
0.5 wt\% GO & 31 & 527 & 23 \\
1 wt\% GO & 25 & 498 & 22 \\
2 wt\% GO & 22 & 426 & 19 \\
3 wt\% GO & 18 & 400 & 15 \\
Nafion 117 & 22 & 160 & 301 \\
(ref. 39) & & & \\
\end{tabular}

function of the water plasticization effect and hydrogen bond interactions, which occur simultaneously at the interface of APN-GO and the SPEN matrix. From Table 1, the tensile strength, tensile modulus, and elongation at break of the APN$\mathrm{GO} / \mathrm{SPEN}$ composite membranes with different filler content in the wet state are slightly higher than that of the GO/SPEN membrane. This is due to the better interfacial interaction of the APN-GO/SPEN membranes than that of the GO/SPEN membranes, which can be also proven via the SEM images. Moreover, the introduction of the cyano group in APN-GO can also enhance the interfacial bond of filler and SPEN matrix, facilitating good interface compatibility. Though the tensile strength and modulus of the APN-GO/SPEN composite membranes present a slight downward trend with the increase of filler content, it is still better than that of Nafion 117 (22 $\mathrm{MPa}),{ }^{39}$ suggesting that the APN-GO/SPEN membrane possesses an outstanding mechanical property, which is high enough for DMFC applications.

\subsection{Proton conductivity}

Proton conductivity is one of the key properties for estimating the fuel cell performance. Fig. 7 shows the proton conductivity of pure SPEN and the APN-GO/SPEN composite membranes at the prescribed temperatures in the full wet state. The detailed

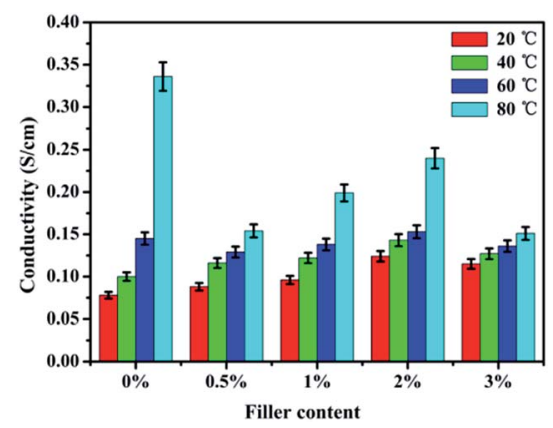

Fig. 7 The influence of APN-GO on proton conductivity with variation of temperature. 
data are also shown in Table 2 . The proton conductivity of the composite membranes increase with an increase in APN-GO content until reaching the highest value $\left(0.124 \mathrm{~S} \mathrm{~cm}^{-1}\right)$ at 2 wt $\%$, and after that, the proton conductivity decreases. This appearance is related to the hydrogen bond interaction and interfacial adhesion between APN-GO and the matrix. The hydrogen bonds act as the proton transmission medium, and are propitious for accelerating the rate of proton transfer, as described schematically in Fig. 8. Fig. 8(b) presents the protonhopping behaviour of pure $\operatorname{SPEN}(\mathrm{b}, \mathrm{I})$ and the composite membranes via the hydrogen bonds at the interface of APN-GO and SPEN (b, II), indicating that the existence of the amide bond is beneficial for fast and effective proton transfer. Moreover, the compatibility and dispersion of APN-GO in the matrix of SPEN are also very important factors for the improvement of proton conductivity. Excellent interfacial adhesion can form continuous proton transport channels, improving the efficiency of proton transfer to achieve enhanced conductivity, such as in 2 wt $\%$ APN-GO/SPEN. However, when the filler content exceeds a certain value, the composite membrane (3 wt\%) exhibits a phase separation phenomenon between the filler and the matrix, resulting in bad interfacial adhesion. The hydrogen bonding interaction is also weakened. This result corresponds to the results from SEM. Table 2 also shows the proton conductivity of the GO/SPEN composite membranes at room temperature. When the content of GO and APN-GO is less than 1 wt $\%$, the proton conductivity of APN-GO/SPEN and GO/SPEN composite membranes shows little difference, which is due to the fact that the low filler content is not sufficient for improving the proton conductivity. However, when the content of GO and APN-GO is more than $1 \mathrm{wt} \%$, the proton conductivity of the APN-GO/SPEN composite membranes is far higher than that of the GO/SPEN membranes, suggesting that the interfacial adhesion and compatibility between the filler and the matrix is better improved by the APN-GO.

Fig. 7 also presents the dependence of proton conductivity of APN-GO/SPEN membranes on different temperatures. Usually, an increase in the temperature can accelerate the rate of proton transport by the way of hopping. Unexceptionally, the APN-GO/ (a)
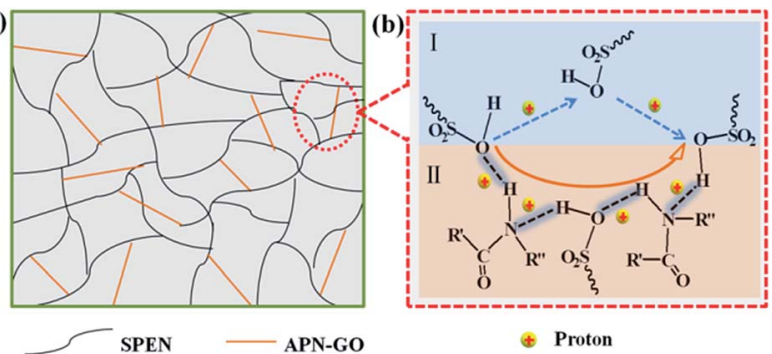

(4) Proton

Fig. 8 Schematic of the interaction between the SPEN matrix and APN-GO

SPEN membranes with different filler content also follow this rule. For the $3 \mathrm{wt} \% \mathrm{APN}-\mathrm{GO} / \mathrm{SPEN}$ membrane at $80{ }^{\circ} \mathrm{C}$, though the water uptake is higher than that of $2 \mathrm{wt} \% \mathrm{APN}-\mathrm{GO} / \mathrm{SPEN}$, the proton conductivity still decreases. This is due to the bad interfacial adhesion of $3 \mathrm{wt} \% \mathrm{APN}-\mathrm{GO} / \mathrm{SPEN}$ membrane, causing greater interfacial penetration. Thus, the membrane cannot be bonded with the protonated propagation medium to form the net transport of protons. Overall, the APN-GO/SPEN composite membranes show excellent proton transfer capability.

\subsection{Methanol permeability and selectivity}

Table 2 lists the methanol permeability of pure SPEN, GO/SPEN and APN-GO/SPEN composite membranes at room temperature. In contrast with pure SPEN, all the composite membranes (GO and APN-GO) possess lower methanol permeation, which may be attributed to the barrier effect of GO. Moreover, the methanol permeability of the composite membranes appear to decline with the addition of APN-GO until the content reaches 2 $\mathrm{wt} \%$ and then the methanol permeability begins to increase, which may be caused by the excellent interfacial adhesion between APN-GO and the matrix. ${ }^{40}$

Within a certain amount of APN-GO, due to the hydrogen bonding interaction between the amide bond and sulfonic acid group, a good interfacial interaction is established between the

Table 2 The proton conductivity, methanol permeation and selectivity of pure SPEN, GO/SPEN and APN-GO/SPEN composite membranes at room temperature

\begin{tabular}{|c|c|c|c|}
\hline Filler content & $\begin{array}{l}\text { Proton conductivity } \\
\left(\mathrm{S} \mathrm{cm}^{-1}\right)\end{array}$ & $\begin{array}{l}\text { Methanol permeation } \\
\left(10^{-6} \mathrm{~cm}^{2} \mathrm{~s}^{-1}\right)\end{array}$ & $\begin{array}{l}\text { Selectivity } \\
\left(10^{5} \mathrm{~S} \mathrm{~cm}^{-3} \mathrm{~s}\right)\end{array}$ \\
\hline SPEN & 0.078 & 0.067 & 1.164 \\
\hline 1 wt\% APN-GO & 0.096 & 0.142 & 6.761 \\
\hline $2 \mathrm{wt} \%$ APN-GO & 0.124 & 0.117 & 10.598 \\
\hline 3 wt $\%$ APN-GO & 0.115 & 0.17 & 6.765 \\
\hline $2 \mathrm{wt} \% \mathrm{GO}$ & 0.092 & 0.359 & 2.563 \\
\hline $3 \mathrm{wt} \% \mathrm{GO}$ & 0.067 & 0.883 & 0.759 \\
\hline Nafion 117 & 0.064 & 1.41 & 0.45 \\
\hline SGO/SPES ${ }^{43}$ & $0.035-0.058$ & $1.55-1.61$ & $2.2-3.7$ \\
\hline GO-his/SPEEK ${ }^{44}$ & $0.063-0.069$ & $0.19-0.39$ & $1.6-4.1$ \\
\hline $\mathrm{SIGO} / \mathrm{SPI}^{45}$ & $0.095-0.114$ & $10.52-16.35$ & $0.58-1.08$ \\
\hline
\end{tabular}


filler and the matrix. However, when the content of APN-GO is in excess, the interfacial adhesion is destroyed by the phase separation phenomenon, resulting in an increased penetration of methanol. Moreover, Table 2 also shows the methanol permeability of the GO/SPEN composite membranes measured at the same condition. The methanol permeability of APN-GO/ SPEN is lower than that of the GO/SPEN composite membranes, demonstrating that the polar nitrile group of APNGO also can increase the interaction between the filler and the polymer matrix, making the membranes more compact, which is beneficial for the reduction of methanol permeability. Though the methanol permeability of the $3 \mathrm{wt} \%$ APN-GO/SPEN membrane has a slight increase, it is still smaller than that of commercial Nafion 117 by an order of magnitude, confirming that the APN-GO is an effective filler for the resistance of methanol.

Selectivity is an important parameter for estimating the performance of membranes used in DMFC. In general, the greater the selectivity, the better the performance is in DMFC. $^{\mathbf{4 1 , 4 2}}$ Table 2 shows that the selectivity of all the composite membranes is higher than that of pure SPEN. The highest selectivity of $2 \mathrm{wt} \%$ APN-GO/SPEN reaches $10.598 \times 10^{5} \mathrm{~S} \mathrm{~S}$ $\mathrm{cm}^{-3}$, whereas of the Nafion 117 membrane, it is $0.45 \times 10^{5} \mathrm{~S} \mathrm{~s}$ $\mathrm{cm}^{-3}$, and is even higher than that of other hybrid membranes listed in Table $2{ }^{43-45}$ suggesting that the APN-GO/SPEN proton exchange composite membranes have great potential in the application of fuel cells.

\section{Conclusion}

In summary, APN-GO/SPEN proton exchange composite membranes have been successfully fabricated via facile solution casting technique, aiming to obtain a high proton conductivity and low methanol permeability simultaneously. In this process, the amide and sulfonic acid groups can form hydrogen bonds, altering the hydrophilic domains and disrupting the original microstructure of pure SPEN. In addition, the membrane with $2 \mathrm{wt} \%$ APN-GO possessed excellent interface compatibility with the SPEN matrix. However, when the filler content exceeded this range, the interfacial adhesion suffered from damage due to phase separation. The water uptake and swelling ratio of the $2 \mathrm{wt} \%$ APN-GO/SPEN composite membranes reached $26.57 \%$ and $11.43 \%$ at $20{ }^{\circ} \mathrm{C}$, respectively, far lower than that of SPEN, indicating that the hydrogen bonding interaction can make the membrane more compact. Furthermore, the proton conductivity of the $2 \mathrm{wt} \%$ APN-GO achieved the highest values of 0.124 and $0.240 \mathrm{~S} \mathrm{~cm}^{-1}$ at $20{ }^{\circ} \mathrm{C}$ and $80{ }^{\circ} \mathrm{C}$, and its methanol permeability reached a value of $0.117 \times 10^{-6} \mathrm{~cm}^{2} \mathrm{~s}^{-1}$ at $20^{\circ} \mathrm{C}$. Therefore, the composite membrane with 2 wt\% APN-GO possessed the highest selectivity $\left(10.598 \times 10^{5} \mathrm{~S} \mathrm{~s} \mathrm{~cm}^{-3}\right)$, which is better than that of pure SPEN and Nafion 117 membranes. It is believed that the as-prepared APN-GO/SPEN composite membrane has great potential for DMFCs applications.

\section{Acknowledgements}

The authors wish to thank the National Natural Science Foundation (No. 51373028) and University of Electronic Science and Technology of China (A03013023601011) for the financial support of this study.

\section{Notes and references}

1 B. C. H. Steele and A. Heinzel, Nature, 2001, 414, 345.

2 S. Subianto, M. Pica, M. Casciola, P. Cojocaru, L. Merlo, G. Hards and D. J. Jones, J. Power Sources, 2013, 233, 216.

3 E. Bakangura, L. Wu, L. Ge, Z. Yang and T. Xu, Prog. Polym. Sci., 2016, 57, 103.

4 M. A. Hickner, H. Ghassemi, Y. S. Kim, B. R. Einsla and J. E. McGrath, Chem. Rev., 2004, 104, 4587.

5 Y. Wang, K. S. Chen, J. Mishler, S. C. Cho and X. C. Adroher, Appl. Energy, 2011, 88, 981.

6 S. J. Peighambardoust, S. Rowshanzamir and M. Amjadi, Int. J. Hydrogen Energy, 2010, 35, 9349.

7 Q. Li, J. F. Jensen, R. F. Savinell and N. J. Bjerrum, Prog. Polym. Sci., 2009, 34, 449.

8 C. H. Park, C. H. Lee, M. D. Guiver and Y. M. Lee, Prog. Polym. Sci., 2011, 36, 1443.

9 H. Zhang and P. K. Shen, Chem. Soc. Rev., 2012, 41, 2382.

10 Y. Gao, G. P. Robertson, M. D. Guiver, S. D. Mikhailenko, X. Li and S. Kaliaguine, Macromolecules, 2005, 38, 3237.

11 Y. Gao, G. P. Robertson, M. D. Guiver, G. Wang, X. Jian, S. D. Mikhailenko, X. Li and S. Kaliaguine, J. Membr. Sci., 2006, 278, 26.

12 S. Y. Lee, N. R. Kang, D. W. Shin, C. H. Lee, K.-S. Lee, M. D. Guiver, N. Li and Y. M. Lee, Energy Environ. Sci., 2012, 5, 9795.

13 D. W. Shin, S. Y. Lee, C. H. Lee, K.-S. Lee, C. H. Park, J. E. McGrath, M. Zhang, R. B. Moore, M. D. Lingwood, L. A. Madsen, Y. T. Kim, I. Hwang and Y. M. Lee, Macromolecules, 2013, 46, 7797.

14 J. Zheng, Q. He, N. Gao, T. Yuan, S. Zhang and H. Yang, J. Power Sources, 2014, 261, 38.

15 Y. S. Kim, M. J. Sumner, W. L. Harrison, J. S. Riffle, J. E. McGrath and B. S. Pivovar, J. Electrochem. Soc., 2004, 151, A2150.

16 M. Guo, B. Liu, S. Guan, L. Li, C. Liu, Y. Zhang and Z. Jiang, J. Power Sources, 2010, 195, 4613.

17 H. Zhang, J. Pang, D. Wang, A. Li, X. Li and Z. Jiang, J. Membr. Sci., 2005, 264, 56.

18 Y. F. Liang, X. L. Zhu and X. G. Jian, Solid State Ionics, 2008, 179, 1940.

19 M. Feng, Y. You, P. Zheng, J. Liu, K. Jia, Y. Huang and X. Liu, Int. J. Hydrogen Energy, 2016, 41, 5113.

20 D. A. Dikin, S. Stankovich, E. J. Zimney, R. D. Piner, G. H. B. Dommett, G. Evmenenko, S. T. Nguyen and R. S. Ruoff, Nature, 2007, 448, 457.

21 D. Chen, L. Tang and J. Li, Chem. Soc. Rev., 2010, 39, 3157. 22 C.-Y. Tseng, Y.-S. Ye, M.-Y. Cheng, K.-Y. Kao, W.-C. Shen, J. Rick, J.-C. Chen and B.-J. Hwang, Adv. Energy Mater., 2011, 1, 1220. 
23 R. Kumar, M. Mamlouk and K. Scott, RSC Adv., 2014, 4, 617. 24 S. Miao, H. Zhang, X. Li and Y. Wu, Int. J. Hydrogen Energy, 2016, 41, 331.

25 Y. He, J. Wang, H. Zhang, T. Zhang, B. Zhang, S. Cao and J. Liu, J. Mater. Chem. A, 2014, 2, 9548.

26 F. Chu, B. Lin, T. Feng, C. Wang, S. Zhang, N. Yuan, Z. Liu and J. Ding, J. Membr. Sci., 2015, 496, 31.

27 G. He, C. Chang, M. Xu, S. Hu, L. Li, J. Zhao, Z. Li, Z. Li, Y. Yin, M. Gang, H. Wu, X. Yang, M. D. Guiver and Z. Jiang, Adv. Funct. Mater., 2015, 25, 7502.

28 Y.-H. Seong, J. Won, S.-K. Kim, K. Nam, S.-K. Kim and D.-W. Kim, Int. J. Hydrogen Energy, 2011, 36, 8492.

29 S. H. Tian, D. Shu, S. J. Wang, M. Xiao and Y. Z. Meng, J. Power Sources, 2010, 195, 97.

30 D. S. Phu, C. H. Lee, C. H. Park, S. Y. Lee and Y. M. Lee, Macromol. Rapid Commun., 2009, 30, 64.

31 H. Guo, Z. Chen, J. Zhang, X. Yang, R. Zhao and X. Liu, J. Polym. Res., 2012, 19, 9918.

32 D. C. Marcano, D. V. Kosynkin, J. M. Berlin, A. Sinitskii, Z. Sun, A. Slesarev, L. B. Alemany, W. Lu and J. M. Tour, ACS Nano, 2010, 4, 4806.

$33 \mathrm{H}$. Beydaghi, M. Javanbakht and E. Kowsarim, Ind. Eng. Chem. Res., 2014, 53, 16621.

34 C. Xu, Y. Cao, R. Kumar, X. Wu, X. Wang and K. Scott, J. Mater. Chem., 2011, 21, 11359.
35 B. Zhang, Y. Chen, X. Zhuang, G. Liu, B. Yu, E.-T. Kang, J. Zhu and Y. Li, J. Polym. Sci., Part A: Polym. Chem., 2010, 48, 2642.

36 X. Wan, Y. Zhan, G. Zeng and Y. He, Appl. Surf. Sci., 2017, 393, 1 .

37 G. Gonçalves, P. A. A. P. Marques, A. Barros-Timmons, I. Bdkin, M. K. Singh, N. Emami and J. Grácio, J. Mater. Chem., 2010, 20, 9927.

38 X. Li, D. Chen, D. Xu, C. Zhao, Z. Wang, H. Lu and H. Na, J. Membr. Sci., 2006, 275, 134.

39 A. K. Mandal, D. Bera and S. Banerjee, Mater. Chem. Phys., 2016, 181, 265.

40 S. Gahlot and V. Kulshrestha, ACS Appl. Mater. Interfaces, 2015, 7, 264.

41 D. W. Shin, S. Y. Lee, N. R. Kang, K. H. Lee, M. D. Guiver and Y. M. Lee, Macromolecules, 2013, 46, 3452.

42 K.-S. Lee, M.-H. Jeong, Y.-J. Kim, S.-B. Lee and J.-S. Lee, Chem. Mater., 2012, 24, 1443.

43 S. Gahlot, P. P. Sharma, V. Kulshrestha and P. K. Jha, ACS Appl. Mater. Interfaces, 2014, 6, 5595.

44 Y. Yin, H. Wang, L. Cao, Z. Li, Z. Y. Li, M. Gang, C. Wang, H. Wu, Z. Jiang and P. Zhang, Electrochim. Acta, 2016, 203, 178.

45 R. P. Pandey and V. K. Shahi, J. Power Sources, 2015, 299, 104. 